\title{
Experimental Investigation of Dynamic Response of Compacted Clayey Soils
}

\author{
Gokhan Inci, Nazli Yesiller, and Takaaki Kagawa
}

\begin{abstract}
A study was conducted to determine the dynamic properties of compacted clayey soils subjected to low amplitude vibration. A fast and simple ultrasonic pulse transmission method was used. Tests were conducted on three clayey soils with low to high plasticity compacted using standard and modified Proctor effort over a range of water contents. The samples were allowed to dry after compaction and P-wave velocity, S-wave velocity, Poisson's ratio, and shear modulus were determined. The effects of soil type, compaction conditions, and degree of saturation on the dy-namic response of the soils were investigated. The elastic wave velocities and the dynamic shear modulus increased as the soil plasticity decreased. The velocities and the modulus increased and the Poisson's ratio decreased as the degree of saturation decreased due to drying. Generally, the ve-locities and moduli increased significantly at the early stages of drying with the changes becoming more gradual as drying progressed. Variations were high for soils compacted with low energy and high water content. The shear moduli of the soils were also estimated using a common empiri-cal equation. Suction values obtained for the test soils in a different study were used as effective stresses in the estimation. The estimated shear mod-uli agreed well with the measured values.
\end{abstract}

\section{Introduction}

Compacted cohesive soils are used commonly in civil engineering to construct embankments, dams, dikes, levees, and liners. Dynamic properties of compacted cohesive soils need to be known to determine the engineering behavior of these soils under dynamic loading and relatively lowintensity cyclic loading. Such loading includes vibrations from machine foundations, pile driving, mov-ing trains and automobiles, as well as vibrations at a distance from earthquakes and conventional blasting operations.

Compaction conditions and post-compaction variations in degree of saturation affect the properties and behavior of compacted cohesive soils. The effects of these conditions on static properties and response of these soils have been studied extensively (Fredlund and Rahardjo 1991; Brown 1996). However, limited information is available on the effects of these conditions on dynamic properties of compacted cohesive soils.

Dynamic properties and response of soils have been studied the-oretically and experimentally for several decades (Hardin and Black 1968, 1969; Hardin and Drnevich 1972; Richart et al. 1970; Hardin 1978; Iwasaki et al. 1978; Goddard 1990). Most of the experimental data available are for granular soils and undisturbed soils. Equations have been developed using results of various testing programs to estimate dynamic response of soils. The common empirical equations proposed for determining the shear modulus of soils are developed using data obtained on dry and saturated sands and saturated cohesive soils (Hardin and Black 1968, 1969; Hardin and Drnevich 1972; Hardin 1978; Iwasaki et al. 1978). Limited work has been done on partially saturated cohesive soils. Gazetas (1991) indicated that at degrees of saturation between 10-50\%, capillary stresses could increase the shear modulus 50-100\% over the values measured on completely dry or 
saturated samples for silty sands.

Tests can be conducted in the laboratory or in the field to deter-mine dynamic properties of soils (Kramer 1996). Examples of lab-oratory dynamic tests include resonant column and ultrasonic pulse transmission tests, which are low-strain tests; and cyclic triaxial, cyclic direct simple shear, and cyclic torsional shear tests, which are high-strain tests. Field tests include seismic reflection and re-fraction, seismic cross-hole, seismic down-hole, suspension type P-S logging, seismic cone, and spectral analysis of surface waves tests, all of which are low-strain tests. The laboratory pulse trans-mission test provides a similar mode of vibration to the field geophysical tests.

This study was conducted to experimentally determine the re-sponse of compacted clayey soils subjected to low amplitude vi-bration using an ultrasonic pulse transmission method. The effects of soil type, compaction conditions, and degree of saturation on the dynamic response of the soils were investigated. The applicability of existing empirical equations for the test soils was assessed.

\section{Background}

Shear modulus, G, is the fundamental parameter that is used to determine the response of soils to small-amplitude vibration (Hardin and Black 1968). Assuming that the medium is semiinfinite and elastic, similar to the assumption provided in Lambe and Whitman (1969) and Richart et al. (1970), shear modulus for soils can be calculated as:

$$
p G \quad 2
$$

where $\mathrm{p}$ is the total density and $V s$ is the shear (S-wave) velocity of the soil mass. Poisson's ratio $(\sim)$ for isotropic materials can be determined as:

$$
\frac{1-{ }^{2}}{2}
$$

With $a=V p / V s$, and $V p$ is the compressional (P-wave) velocity.

The shear modulus for isotropic materials can also be determined usingPoisson'ss ratio and constrained modulus, $D$, as:

$$
\frac{D G 1-2)}{21-J}
$$

where $D$ is calculated as 
Deformation moduli and damping factors for sands and clays have beereported based on the findings ovariousus laboratory and fielstudies. Variousuempiricalal equations are available testimatet dynamicic shear modulus of soils. For example, based on extensive series of resonancolumnntests, Iwasaki etet al. (1978) showed that the small-strain shear modulus, Gmax, for sands can be approxi-mated by the following equation:

$$
90 \frac{2.17-)^{2}}{1} \sigma G^{38} \quad 10^{2} \quad \mathrm{~Pa}
$$

where $e$ is the void ratiand oisis the effective mean principa stress. $G_{\text {maxa }}$ and oare both in kPa. Hardin (1978) developed a similar empirical equation for sands and clays based also on resonant column tests as:

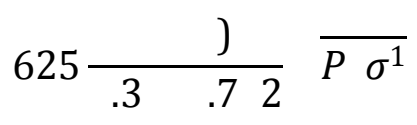

where $O C R$ is the overconsolidation ratio, $\mathrm{p}$ is a parameter that de-pends on the plasticity index, $P a a$ is the atmospheric pressure Gmax, $O$, and $P a$ a in Eq 6 must be in consistent units, e.g., $\mathrm{kPa}$. The cohesive soils used in the test programs for the development of Eq 6 were remolded standard kaolinite and various undisturbed soil (Hardin and Blackc1968, 1969; Hardin and Drnevichc1972). The re-searchersrs identified degree of saturation as one of the parameters thaaffecteded shear modulus. However, the saturation was essen-tiall $100 \%$ inin the test soils that were used in the development of Eq 6. The equation was originally developed using tests on satu-ratekaolinite (Hardinin and Black 1968). Further verification was provided for the equation using results of tests on undisturbed cohesive soils with degrees of saturation between 98-100 \% withith th exceptionon of one soil, which had a degree of saturation o87 \%7 (Hardindin anDrnevichch 1972). Hardin (1978) and Hardin and Blandford (1989) also provided semi-empiricalal equation to determine shear modulus for specific stress paths for advanced threedimensional analysis of small strain deformation of soils. This approach requires the use oPoisson's's ratio and dimensionlessss elas-tistiffnessss coefficient in addition to the parameters presented in Eq 6. Limited information is available on the stiffness coefficients for partially saturated, compactesoils. Whilele the abovequationsns provide a rational basis testimatete the shear modulus of partially saturated clayey soils, predictions have not commonly beere-porteded for these soils.

Dynamic properties and response of compacted cohesive soils have not been investigated as extensively as the static properties and response of these soils. Limited information is available on the effects of 
compaction conditions and post-compaction variation on dynamicic elastic properties of compacted clayey soils. Sheeran et al. (1967) conducted a study to correlate P-wave velocities of compacted clayey soils to compaction conditions. At constant wa-ter content, velocity increased with dry density until a maximum was reached. The velocity decreased sharply at increasing densities beyond this point. Peak velocities and maximum dry densities oc-currewithin $\pm 0.5 \%$ waterer content. The researchers pointed out possibledgee effects on the measured velocities in small compaction molds and effects resulting from the method of com-paction. They also investigated the effects of drying on the veloc-ity. For a samplprepareded at dry ooptimum, thethe velocity increased with drying until the water content decreaseapproximatelyly below thshrinkagege limit with no significant change observed beyond this point

Stephensono (1978) reported P-wave and S-wave velocities and dynami Young's's and shear moduli for a compacted low-plasticity silty clay. Samples were prepared at varying void ratios and degrees of saturation. Wave velocities of the samples were mea-sured immediately after compaction. The study by Stephenson (1978) showed that the wave velocities and thus thYoung's's mod-ulus and the shear modulus increased with increasing degree of saturation for a given void ratio. Furthermore, wave velocities and the moduli decreased with increasing void ratio for a given degree osaturation.n.

Ultrasonic pulse transmission methods have been used effectively to measure P-wave and S-wave velocities of soils in the lab-oratory and in the field (e.g., Sheeran eal. 1967; Stephensonon 1978; Cockaerts and De Cooman 1994; Brignoli et al. 1996; Nakagawa et al. 1996; Fioravante 2000). Measured wave velocities have been used to infer physical conditions and elastic properties of soils such adensity, porosity, strength, stiffness, andand anisotropy. Ultrasonic tests provide a fast and simple means to determine wave velocities nondestructively. Wave travel times through the fastest possible paths in soil masses are measured using these tests (Nakagawa et al. 1996). Therefore, ultrasonic methods tend to yield higher wave velocities and deformation moduli compared to laboratory element tests (e.g., resonant column and cyclic triaxial), which provide overall average stiffness of soil samples. For highly heterogeneou soils withth greavariationon in velocity, ultrasonic tests may overestimathe dynamicic response of the overall soil mass. Nakagawa et al. (1996) reported good agreement between S-wave velocities measured in thlaboratory within a pulse transmission method and in the field with suspension type S-wave logging. On the other hand, there wersignificantandifferenceses between laboratory resonancol-umnnm measurements and the field data particularly for clay soils. Laboratory pulse transmission tests provide a direct means for es-tablishing correlations to field seismic tests that are commonly used for determining dynamic response of soils on a field scale.

In this study, an ultrasonic method was used to determine P-wave and S-wave velocities in three compacted clayey soils with low to high plasticity. The effects of soil type and compaction conditions othe dynamicic response of the soils were assessed in the laboratory. The soils were allowed to dry subsequent to compaction to investigate the effects of saturation level on measured dynamic properties. In addition, the use of the common empirica approachch was investigated to predict the shear modulus of the soils.

\section{Testing Program}


The testing program consisted of determination of physical properties and P- and S-wave velocities of compacted clayey soils in the laboratory. The samples were allowed to dry subsequent to compaction under standard laboratory conditions to vary the de-gree of saturation in the soils. The drying period (approximately 75 days) continued until the water content of the soils decreased below $3 \%$. The volume change of the soils had ended well before the samples attained the low water contents. Measurements were made during the drying period to calculate dynamic elastic parameters for the soils.

\section{Materials}

The tests were conducted on three types of soils. Soils 1 and 2 were low plasticity natural soils obtained from southeast Michigan. Soil 2 was mixed with $25 \%$ bentonite by weight to make Soil 3 with high plasticity, to broaden the type of soils tested in the study. The engineering properties of the test soils are presented in Table 1. Mineralogical analysis was not conducted on the soils. However, it is believed that the natural soils are representative of the typical soils of this geographical region that contain predominantly illite in the clay portion (Yesiller et al. 2000b).

\section{Samples}

Tests were conducted on cubical and cylindrical samples com-pacted using standard and modified Proctor effort. The cubical samples had dimensions of approximately $110 \mathrm{~mm}$. These samples were initially prepared in 150-mm-diameter and 300-mm-high cus-tom compaction molds using equivalent standard or modified Proc-tor effort. These samples were then cut and trimmed to the $110 \mathrm{~mm}$ cubical sample sizes. The cubical samples were prepared at wet of optimum, optimum, and dry of optimum water contents for each soil type and compaction condition. The cylindrical samples were prepared in standard Proctor molds with approximately $100 \mathrm{~mm}$ radial and $110 \mathrm{~mm}$ axial dimensions. These samples were prepared at wet of optimum water contents for each soil type and compaction condition. A total of 18 cubical and 6 cylindrical samples were pre-pared for the testing program.

\section{Determination of Wave Velocities}

A measurement system that consisted of commercially available velocity transducers, a pulser-receiver, and a PC-based data acqui-sition setup was used for the study (Fig. 1). The transducers and the pulserreceiver are manufactured by Panametrics Inc.3 (P-Wave Transducer: Model X1 021, S-Wave Transducer Model V1 548,

Pulser-Receiver: Model 5058) and the data acquisition system is available from Sonix Inc.3 (Model STR 8100D). The velocity transducers included P- and S-wave transducers. The P-wave measurements were made using 50-kHz-center frequency narrowband transducers. The S-wave measurements were made using $100-\mathrm{kHz}$-center frequency normal incidence shear wave transducers. The transducers were actuated by a high voltage (adjustable up to 900V) pulser-receiver, which was connected to a PC. The $10 \mathrm{MHz}$ bandwidth broadband pulser-receiver had an adjustable repetition rate in the range of $20 \mathrm{~Hz}$ to $2 \mathrm{kHz}$, with a one-volt output for synchronous triggering of the signal acquisition board during data collection. The transducers and the pulser-receiver used are particularly suited for testing highly attenuating, difficult to penetrate materials. The data acquisition system included a PC with an A/D (analog to digital) converter board with up to $100 \mathrm{MHz}$ sampling rate and a digital oscilloscope software package to inspect wave-forms 
and to adjust data acquisition parameters. Details of the measurement system and the waveform analysis procedures are presented in Inci (2001).

Two transducers were used for each type of velocity measurement. A transmitting transducer was placed on one end of a sample, and a receiving transducer was placed on the opposite end of the sample (Fig. 1). Examples of waveforms obtained in the study are presented in Fig. 2. Wave velocity was determined as the quotient of the travel path (the length of the samples) to the travel time of the waves of interest. The length of the samples was determined using a pair of calipers with a resolution of $0.02 \mathrm{~mm}$. The travel time for the waves was calculated as the difference between the time of application of the pulse by the transmitting transducer and the arrival time of the signal at the receiving transducer. The oscilloscope window was maintained at 40 ps for the measurements (similar to the P-wave signal presented in Fig. 2). Each waveform consisted of 1000 data points resulting in a resolution of 0.04 ps for the travel time measurements. This yielded a maximum theoretical error (Bardet 1997) of less than $0.1 \%$ in the wave velocity measurements. The exact wave arrival times were determined using waveform averaging and statistical analysis techniques (Inci 2001). A threshold amplitude was set using the earlier portions of the waveforms. The time corresponding to the first point in a wave-form that was significantly higher than the threshold amplitude was recorded as the wave arrival time. The test setup and procedures used are similar to the methodology that is presented in ASTM D2845 (Standard Test Method for Laboratory Determination of Pulse Velocities and Ultrasonic Elastic Constants of Rock).

Both types of transducers used in the study were plate element transducers. These transducers were selected over bender element transducers due to the simplicity of use and the suitability to the test program. Multiple repeated measurements were required to be made on various samples over time in the test program. The plate transducers were used without disturbing the samples during a measurement (Fig. 1) and were readily transferred from one sam-ple to another upon completion of a measurement.

The effectiveness of the ultrasonic setup used in the study was verified by measurements conducted on Ottawa sand. Samples were prepared in 15-cm-long sections of Shelby tubes to specific void ratios and subjected to specific stresses. The measurements obtained on the samples (Table 2) were compared to velocities re-ported by Lambe and Whitman (1969). Results indicated that at similar void ratios and stress conditions, wave velocities obtained with the measurement system agreed well with the published values (Lambe and Whitman 1969, comparisons are with Fig. 30.1 for P-wave velocities and with Fig. 12.10 for S-wave velocities). In ad-dition, the waveforms obtained and the arrival times identified for the different types of transmitted waves (Fig. 2) agreed well with the examples presented in Brignoli et al. (1996).

\section{Drying Procedures}

The soils were allowed to dry in standard laboratory temperature and humidity conditions. The samples were extracted from the compaction molds and allowed to air dry with no forced drying (e.g., heat or blowing air application). Samples dried uniformly with similar radial and axial strains and cracking was not observed. The color of the soils was uniform across the radial and axial di-rections of the samples during drying. Therefore, it is believed that the saturation in the samples was relatively uniform across the ra-dial 
and axial directions (this assumption was not numerically quantified).

The weight and dimensions of the samples were measured dur-ing drying in addition to the measurements of the P- and S-wave velocities. The weights of the samples were measured using a bal-ance with a resolution of $0.1 \mathrm{~g}$. Radial and axial dimensions of the samples were determined along various spans using a pair of calipers with a resolution of $0.02 \mathrm{~mm}$. It was assumed that the weight and volume change occurred in the samples during drying due solely to loss of water (extreme care was taken not to disturb the samples during drying). The weight and volume measurements and the previously measured specific gravities (Table 1) were used to determine the degrees of saturation for the samples based on ba-sic phase relationships for soils.

\section{Complimentary Tests}

Total suctions were measured in samples of the three test soils in an associated drying study (Fig. 3). Samples were compacted in 450-mm-diameter and 150-mm-high molds at wet and dry of opti-mum water contents using equivalent standard compaction effort. Total suction measurements were obtained at three depths in the samples with two psychrometers located at each measurement depth. A maximum of six measurements were obtained for a sam-ple at a given testing time (and corresponding water content). The water contents of the samples were determined during dying by monitoring the weight of the samples. Some of the psychrometers installed in the dry of optimum samples failed during the tests and less data is available for these samples at a specific water content compared to the wet of optimum samples (Fig. 3).

Consolidation tests were also conducted on samples of the test soils to determine the OCR for the soils. The samples were prepared at the same compaction conditions as the samples that were used for the determination of the dynamic elastic properties of the soils. Details of the consolidation tests are provided in Inci (2001).

\section{Results and Discussion}

In this section, first measured wave velocities and physical char-acteristics (volumetric strain, void ratio, total density) of the soils are presented. Then, dynamic elastic properties, Poisson's ratio andshear modulus, of the soils are presented.

\section{Wave Velocities}

The basic theoretical analyses for wave transmission in porous media are presented by Biot (1956a, b). Calculations and verifications of theoretical predictions are presented in Gazetas (1991) and Albert (1992). Shear waves are transmitted through the soil skeleton in a soil mass at all degrees of saturation and compressional waves are transmitted through the soil skeleton when the degree of saturation is below 99 \% (i.e., when air is introduced into the fluid phase, with saturations between 99 and $100 \%$ representing a transition phase) [Gazetas 1991].

The P- and S-wave velocities obtained in the tests are presented in Fig. $4 a$ and $b$, respectively. The variation of velocities is presented as a function of average degree of saturation, since saturation is a 
normalized term compared to time (drying rate dependent) and water content (soil type dependent). The measured velocities are generally within the range of published values for clays ( $\mathrm{P}$-wave $=900-2800$ $\mathrm{m} / \mathrm{s}$ for clays, Gazetas 1991; P-wave $=1500 \mathrm{~m} / \mathrm{s}$, S-wave $=150 \mathrm{~m} / \mathrm{s}$ for moist clay, Prakash 1981). However, the velocities, particularly the S-wave velocity increased due to drying beyond values reported in the literature as described below. The variation of volumetric strain, void ratio, and total unit weight with saturation are presented in Fig. $5 a, b$, and $c$, respectively.

Wave velocities of compacted clayey soils can be affected by a number of parameters that include both compositional and environmental factors. The compositional factors include clay mineralogy and fines content. The environmental factors include compaction conditions and characteristics, degree of saturation, and effective stresses in a sample. The initial response of the soils was based on the compositional factors and compaction conditions whereas the environmental factors were predominant during drying. The velocities increased with increasing compaction effort and decreasing soil plasticity. On the day of compaction, the velocities were generally high for optimum water content and low at both the dry and wet side of the optimum. The highest velocities were obtained for the samples of Soil 1 (lowest clay content and plasticity) that were compacted with modified effort at the optimum water content. These samples had the highest solids and lowest void contents in the testing program. Similar observations were made for the test soils in another study (Yesiller et al. 2000a).

Wave velocities are a function of the effective stresses in a soil mass as presented in the empirical relations (Eqs 5 and 6). Suctions (i.e., negative excess porewater pressures) that are inversely proportional to saturation in soils, control effective stresses in unsatu rated soils (Fredlund and Rahardjo 1991). Increases in suction cause increases in the stiffness of the soils and resulting increases in the velocities of waves transmitted through the skeletons of the soil masses. Soil type and compaction conditions affect the magnitudes of suctions that can develop in soils (Tinjum et al. 1997; Miller et al. 2002 The velocities of all the samples increased with drying. The change in velocity due to drying was a function of both compaction water content and compaction effort and was affected significantly by the suctions in the soils. The highest variation in velocities oc-curred in the wet of optimum samples, whereas the lowest variation occurred in the dry of optimum samples (Fig. 4). The saturations decrease a large amount for the wet of optimum soils, yet decrease much less for the dry of optimum soils due to drying. High varia-tions in suctions were observed for the wet of optimum samples as a result of the high variations that occurred in the water contents and saturations of these samples during drying. Low variations in suctions were observed for the dry of optimum samples as low vari- ations occurred in the water contents and saturations of these samples (Fig. 3). The volumetric strain, void ratio, and total unit weight also varied significantly for the wet of optimum soils (Fig. 5). Tin-jum et al. (1997) reported high variation in suctions for wet of op- timum soils in their study of desaturation of compacted cohesive soils. Desaturation behavior of the three test soils was determined using pressure plate tests (Miller et al. 2002). The variation of suction with saturation was higher for the wet of optimum test soils than for the dry of optimum test soils.

In addition, the variation in velocity was generally somewhat higher for soils compacted with standard effort than the soils com-pacted with modified effort. Generally higher variations occurred in the void ratio, volumetric strain, and unit weight of the samples compacted with standard effort than the samples 
compacted with modified effort (Fig. 5). The samples prepared using standard effort have high amounts of water that can be lost during drying re-sulting in high variations in these physical properties as well as suction and thus effective stress. The suction in a standard Proctor sample increased more over the same amount of moisture loss than a modified Proctor sample in the results presented by Tinjum et al. (1997). The suctions were somewhat higher for samples compacted with modified effort compared to samples compacted with stan-dard effort at the same volumetric water content for the test soils (Miller et. al 2002). In addition, desaturation started at high matric suctions for soils compacted with high effort and high water con-tent (Tinjum et al. 1997; Miller et al. 2002).

The measured ultrasonic velocity response for the test soils demonstrated three stages of behavior during drying. A sharp in-crease in velocity was generally observed at the beginning of the drying process. This was followed by a period of gradual increase in measured velocity and a final sharp increase in velocity at the end of the drying period. The suctions increased significantly in the large samples of the test soils during the early stages of drying (ob-served when suctions in Fig. 3 are plotted as a function of time as presented in Inci 2001). This can lead to high increases in volumetric strain and corresponding decreases in void ratio. These ini-tial changes due to drying caused the initial high increases in ve-locities (Fig. 4).

Upon further drying, desaturation becomes progressively more difficult because as the water content decreases, water retreats into smaller and smaller pores, and the air phase becomes continuous. The release of water out of the samples becomes difficult as the wa-ter conductivity decreases and air conductivity increases (Fredlund and Rahardjo 1991). This can slow down the increases in suction at the later stages of drying for wet samples and also prevent high in-creases in suction at low degrees of saturation. The samples at-tained relatively constant volume during this second phase of dry-ing and the velocities did not vary significantly. This phase can correspond to the relatively constant slope, mid-section of typical soil-water characteristic curves.

A further increase in velocity was observed at the end of the dry-ing period although the variation in the physical properties have sta-bilized. In different studies, it was observed that suctions in com-pacted clayey soils continued to increase over extended periods of time similar to the durations of this study (Yesiller et al. 2000b; Inci 2001). Desaturation of the smallest pores in the samples can be oc-curring at the end of the drying period with suctions increasing to very high levels. This increase may not be sufficient to change the volume of the soils beyond a certain level (e.g., at water contents below shrinkage limit), however, this still affects the stiffness of the samples. The final increases in the stiffness of the samples may have been responsible for the increase in the velocities during the final stage of drying. This is also observed in soilwater characteristic curves, where the suctions increase significantly with very small changes in volumetric water content (or saturation) near the resid-ual water content (Fredlund and Rahardjo 1991). Further studies are needed to clarify the microscopic structure of soils undergoing dry-ing; such studies were outside the scope of this investigation.

\section{Elastic Parameters}

Poisson 's Ratio-Poisson's ratios (Fig. 6) were calculated using P- and S-wave velocities (Eq 2). It was assumed that the medium was isotropic, semi-infinite, and elastic similar to the assumption provided in 
Richart et al. (1970). Linear envelopes are used to represent the approximate upper and lower boundaries of the measured data (Fig. 6). The initial values for wet samples ranged between 0.4 and 0.5 and the values decreased to 0.1-0.2 at the end of drying. Published values for Poisson's ratios for clayey soils are: 0.25 - (stiff clays), 0.40 - (nearly saturated clays above the water table), 0.5 (sat-urated clays and sands beneath the water table) [Gazetas 1991]; 0.1-0.3- (unsaturated clay), 0.4-0.5- (saturated clay), 0.2-0.3- (sandy clay) [Bowles 1988]. The Poisson's ratios measured in the tests are in good agreement with the published data for clays.

The Poisson's ratios depended highly on the degree of saturation and slightly on the plasticity of the soils. The Poisson's ratios increased with increasing saturation and the variation in Poisson's ratio was lower at high saturations compared to low saturations. The variation in Poisson's ratio was slightly less for Soil 1 compared to Soils 2 and 3. Gazetas (1991) indicated that Poisson's ratio depended highly on degree of saturation and was slightly affected by soil type, confining pressure, and void ratio. Saturated soils are essentially incompressible with corresponding limiting Poisson's ratios approaching 0.5 . As the saturation levels decrease and the water phase becomes discontinuous the compressibility of soils increases. It is believed that the compressibilities of the test soils were affected by the structure of soils in addition to saturation at low saturation levels. Variations in structure (e.g., resulting from initial compaction conditions, development of suctions, etc.) resulted in a high range of compressibility and thus Poisson's ratio at the low saturations. The observations for Poisson's ratio agreed well with the trends and data provided in the literature (Bowles 1988; Gazetas 1991).

Shear Modulus - Shear moduli for the test soils were calculated using the measured shear wave velocity and measured total density using Eq 1 . These values are referred to as measured shear moduli (Fig. 7). The measured moduli are generally higher than the published values for natural clays. The published values are: 9-15 MPa for wet soft silty clay; 17-2 1 MPa for dry soft silty clay; 25-35 MPa for dry silty clay; 12-30 MPa for sandy clay (Bowles 1988).

The moduli increased with increasing compaction effort, decreasing soil plasticity, and decreasing water content similar to the observations for velocities. The trends observed for the moduli during drying were similar to the trends observed for velocities during drying. The shear modulus increased due to drying with the highest increases obtained for wet of optimum soils and lowest changes obtained for dry of optimum soils. The initial changes in moduli were high, generally followed by a gradual change and a final in-crease at the end of the drying periods. The order and variation of shear moduli are affected by the same compositional and environmental factors that influence wave velocities.

The shear modulus was also estimated using the formulation provided in Eq 6. Fredlund and Rahardjo (1991) suggest the use of two stress state variables [( $\alpha-u a)$ external stress and (ua-uw) matric suction] to analyze unsaturated soils. A simplified approach was adopted and the effective stresses in the test soils were estimated using suctions measured in the test soils. A single stress value was used in Eq 6 to estimate the shear modulus of the test soils. While good agreement was observed between the measured and predicted shear moduli (as presented below), additional studies are required to further verify the validity of this approach. 
The matric suctions in the soils were estimated by subtracting osmotic suction from the measured total suctions. A constant osmotic suction of $300 \mathrm{kPa}$ was used; this value was selected based on the data provided in Fredlund and Rahardjo (1991). Suctions were not available for the soils compacted with modified effort and results from standard compaction samples were used for all of the test soils. Matric suctions are presented in Fig. 8. Suctions are provided as a function of saturation in the soils to be consistent with the remainder of the data presented in the paper.

The shear moduli for the test soils were predicted using Eq 6. The effective stresses (matric suctions) were determined from Fig. 8 and void ratios were determined from Fig. $5 c$ using the satura-tions of the samples. In the consolidation tests, it was determined that the void ratios of the samples were along the virgin consolidation line for all soil types (Inci 2001). Therefore, the OCR value was set equal to 1 for all the soils in Eq 6. The predicted shear modulus values for the soils are presented in Fig. 9.

The measured shear modulus values are compared with the esti-mated values in Fig. 10. It was observed that the estimated values were in good agreement with the measured data. Better estimations may be obtained by conducting more extensive suction determinations. These include direct measurement of total suctions and osmotic suctions on the test samples. In addition, more advanced theoretical analysis is required to determine the shear modulus of unsaturated soils using two stress state variables. Shear modulus estimations may also be improved by considering time effects.

Time-dependent increases up to $25 \%$ per logarithmic cycle of time were obtained in shear modulus of cohesive soils (Afifi and Woods 1971; Anderson and Woods 1976). Air-dry and high saturation cohesive soils were tested in the laboratory by resonant column tests at constant confining stresses. The time-dependent effects were estimated to have occurred due to thixotropic changes in the structure of the soils (Anderson and Woods 1976). Isolation and analysis of time effects on the test soils during drying were beyond the scope of this study. It is believed that the common empirical approach for determining shear modulus provided good agreement to the measured data with the use of matric suctions as effective stresses in the predictive equation.

\section{Summary and Conclusions}

Measurements of P- and S-wave velocities were made on three types of compacted clayey soils using a fast and simple ultrasonic method. The soils were compacted using standard and modified Proctor efforts over a range of water contents. The soils were allowed to dry subsequent to compaction to vary the degree of saturation in the soils. P-wave and S-wave velocities were measured to determine Poisson's ratio and shear modulus of the soils. The effects of soil type, compaction conditions, and the de-gree of saturation on the dynamic response of the soils were in-vestigated.

The ultrasonic method was effective for measuring P- and S- wave velocities in the test soils. The velocity and modulus increased as the plasticity of the soils decreased. Compaction conditions and degree of saturation affected the dynamic response of the soils significantly. The dynamic shear 
modulus increased and the Poisson's ratio decreased due to drying as the degree of saturation in the soils decreased. For shear modulus, generally, there was a high increase at the early stages of drying followed by more gradual changes as drying progressed. Variations in modulus were high for soils compacted with low energy and high water content. The wave velocities and shear moduli did not change significantly for soils compacted at low water contents.

Comparisons were made between the measured shear modulus and shear modulus estimated using a common empirical equation. Suction values obtained for the test soils in a complimentary study were used as effective stresses in the estimation. The estimated shear moduli agreed well with the measured values. Further stud-ies are needed to verify the validity of this approach to additional partially saturated soils.

Acknowledgment

This study was conducted as part of a project funded by the Na-tional Science Foundation (Grant No. CMS-9713922).

\section{References}

Albert, D. G., 1992, "Comparison Between Wave Propagation in Water Saturated and Air Saturated Porous Materials," Journal of Applied Physics, Vol. 73, No. 1, pp. 28-36.

Afifi, S. S. and Woods, R. D., 1971, "Long-Term Pressure Effects on Shear Modulus of Soils," Journal of the Soil Mechanics and Foundations Division, ASCE, Vol. 97, SM10, pp. 1445-1460.

Anderson, D. G. and Woods, R. D., 1976, "Time-Dependent In-crease in Shear Modulus of Clay," Journal of the Geotechnical Engineering Division, ASCE, Vol. 102, No. GT5, pp. 525-537.

ASTM D2845-90, 1998, "Standard Test Method for Laboratory Determination of Pulse Velocities and Ultrasonic Elastic Con-stants of Rock," Annual Book of ASTM Standards, ASTM Inter-national, West Conshohocken, PA.

Bardet, J. P., 1997, Experimental Soil Mechanics, Prentice-Hall, Upper Saddle River, NJ.

Biot, M. A., 1956a, "Theory of Propagation of Elastic Waves in a Fluid Saturated Porous Solid, 1. Low-Frequency Range," Jour-nal of Acoustical Society of America, Vol. 28, No. 2, pp. 168-1 78.

Biot, M. A., 1956b, "Theory of Propagation of Elastic Waves in a Fluid Saturated Porous Solid, 2. Higher Frequency Range," Journal of Acoustical Society of America, Vol. 28, No. 2, pp. 179-191.

Bowles, J. E., 1988, Foundation Analysis and Design, McGraw Hill, Singapore.

Brignoli, G. M., Gotti, M., and Stokoe, K. H. II, 1996, "Measure-ment of Shear Waves in Laboratory Specimens by Means of Piezoelectric Transducers," Geotechnical Testing Journal, Vol. 19, No. 4, pp. 384-397.

Brown, R. W., 1996, Practical Foundation Engineering Hand-book, McGraw-Hill, New York, NY. 
Cockaerts, G. and De Cooman, P., 1994, "Measuring Wave Propa-gation Characteristics in Artificial Sand-Clay Mixtures," Sur-veys in Geophysics, Vol. 15, No. 5, pp. 495-5 13.

Fioravante, V., 2000, "Anisotropy of Small Strain Stiffness of Ti-cino and Kenya Sands from Seismic Wave Propagation Mea-sured in Triaxial Testing," Soils and Foundations, Japanese Geotechnical Society, Vol. 40, No. 4, pp. 129-142.

Fredlund, D. G. and Rahardjo, H., 1993, Soil Mechanics for Un-saturated Soils, John Wiley \& Sons, New York, NY.

Gazetas, G., 1991, “Foundation Vibrations,” Foundation Engi-neering Handbook, Ch. 15, H. Y. Fang, Ed., Van Nostrand Rein-hold, New York, NY, pp. 553-593.

Goddard, J. D., 1990, “Nonlinear Elasticity and Pressure-Depen-dent Wave Speeds in Granular Media," Proc. Royal Society Lon-don Series A, Vol. 430, pp. 105-131.

Hardin, B. O., 1978, “The Nature of Stress Stain Behavior of Soils," Earthquake Engineering and Soil Dynamics, ASCE, Vol. 1, pp. 3-90.

Hardin, B. O. and Black, W. L., 1968, "Vibration Modulus of Nor-mally Consolidated Clay," Journal of the Soil Mechanics and Foundations Division, ASCE, Vol. 94, SM2, pp. 353-369.

Hardin, B. O. and Black, W. L., 1969, "Vibration Modulus of Nor-mally Consolidated Clay; Closure," Journal of the Soil Mechan-ics and Foundations Division, ASCE, Vol. 95, SM6, pp. 153 1-1537.

Soil Mechanics and Foundations Division, ASCE, Vol. 98, SM7, pp. 667-692. Inci, G., 2001, Nondestructive Evaluation of Compacted Clayey Soils, Ph.D. Dissertation, Wayne State University, MI.

Iwasaki, T., Tatsuoka, F., and Takagi, Y., 1978, "Shear Moduli of Sands Using Cyclic Torsional Shear Loading," Soils and Foun-dations, Japanese Society of Soil Mechanics and Foundation En-gineering, Japan, Vol. 18, No. 1, pp. 39-56.

Kramer, S. L., 1996, Geotechnical Earthquake Engineering, Pren-tice Hall, Upper Saddle River, NJ.

Lambe, T. W. and Whitman, R. V., 1969, Soil Mechanics, John Wiley \& Sons, New York, NY.

Miller, C. J., Yesiller, N., Yaldo, K., and Merayyan, S., 2002, "Im-pact of Soil Type and Compaction Conditions on Soil Water Characteristic," Journal of Geotechnical and Geoenvironmental Engineering, ASCE, Vol. 128, No. 9, pp. 73 3-742.

Nakagawa, K., Soga, K., and Mitchell, J. K., 1996, "Pulse Trans-mission System for Measuring Wave Propagation in Soils," Journal of Geotechnical Engineering, ASCE, Vol. 122, No. 4, pp. 302-3 08.

Prakash, S., 1981, Soil Dynamics, McGraw Hill, New York, NY.

Richart, F. E., Hall, J. R., and Woods, R. D., 1970, Vibrations of Soils and Foundations, Prentice-Hall, Upper Saddle River, NJ. 
Sheeran, D. E., Baker, W. H., and Krizek, R. J., 1967, "Experi-mental Study of Pulse Velocities in Compacted Soils," Highway Research Record No. 177, Highway Research Board, pp. 226-238.

Stephenson, R. W., 1978, “Ultrasonic Testing for Determining Dy-namic Soil Moduli,” Dynamic Geotechnical Testing, ASTM STP 654, ASTM International, West Conshohocken, PA, pp. 179-195.

Tinjum, J. M., Benson, C. H., and Blotz, L. R., 1997, "Soil-Water Characteristic Curves for Compacted Clays," Journal of Geotechnical Engineering, ASCE, Vol. 123, No. 11, pp. 1060-1069.

Yesiller, N., Inci, G., and Miller, C. J., 2000a, "Ultrasonic Testing for Compacted Clayey Soils," Advances in Unsaturated Geotechnics, Geotechnical Special Publication 99, C. D. Shack-elford, S. L. Houston, and N.-Y. Chang, Eds., ASCE, pp. 54-68.

Yesiller, N., Miller, C. J., Inci, G., and Yaldo, K., 2000b, “Desic-cation and Cracking Behavior of Three Compacted Landfill Liner Soils,” Engineering Geology, Elsevier, Vol. 57, pp. 105-121. 
TABLE 1-Engineering properties of test soils.

\begin{tabular}{|c|c|c|c|c|c|c|}
\hline Soil Property & \multicolumn{2}{|c|}{ Soil 1} & \multicolumn{2}{|c|}{ Soil 2} & \multicolumn{2}{|c|}{ Soil 3} \\
\hline Classification (USCS) & \multicolumn{2}{|c|}{$\mathrm{SC}$} & \multicolumn{2}{|c|}{ CL } & \multicolumn{2}{|c|}{ CH } \\
\hline \multicolumn{7}{|l|}{ Particle size ( $\%$ by weight) } \\
\hline Sand & \multicolumn{2}{|c|}{56} & \multicolumn{2}{|c|}{3} & \multirow{2}{*}{\multicolumn{2}{|c|}{2}} \\
\hline Silt & \multirow{2}{*}{\multicolumn{2}{|c|}{$\begin{array}{l}27 \\
17\end{array}$}} & \multicolumn{2}{|c|}{38} & & \\
\hline Clay & & & & & \multicolumn{2}{|c|}{69} \\
\hline \multicolumn{7}{|l|}{ Atterberg limits } \\
\hline LL (\%) & \multicolumn{2}{|c|}{16} & \multicolumn{2}{|c|}{40} & \multicolumn{2}{|c|}{81} \\
\hline PI (\%) & \multirow{2}{*}{\multicolumn{2}{|c|}{7}} & \multirow{2}{*}{\multicolumn{2}{|c|}{$\begin{array}{l}17 \\
2.68\end{array}$}} & \multicolumn{2}{|c|}{$\stackrel{55}{269}$} \\
\hline Specific gravity & & & & & & \\
\hline Compaction effort & Std. ${ }^{1}$ & Mod. $^{2}$ & Std. & Mod. & Std. & Mod. \\
\hline Max. dry unit weight $\left(\mathrm{kN} / \mathrm{m}^{3}\right)$ & 20.5 & 21.6 & 15.9 & 18.2 & 15.3 & 16.7 \\
\hline Optimum water content (\%) & 9 & 7.2 & 22 & 15 & 25 & 19 \\
\hline
\end{tabular}

\footnotetext{
${ }^{1}$ Standard Proctor compaction.

${ }^{2}$ Modified Proctor compaction.
}

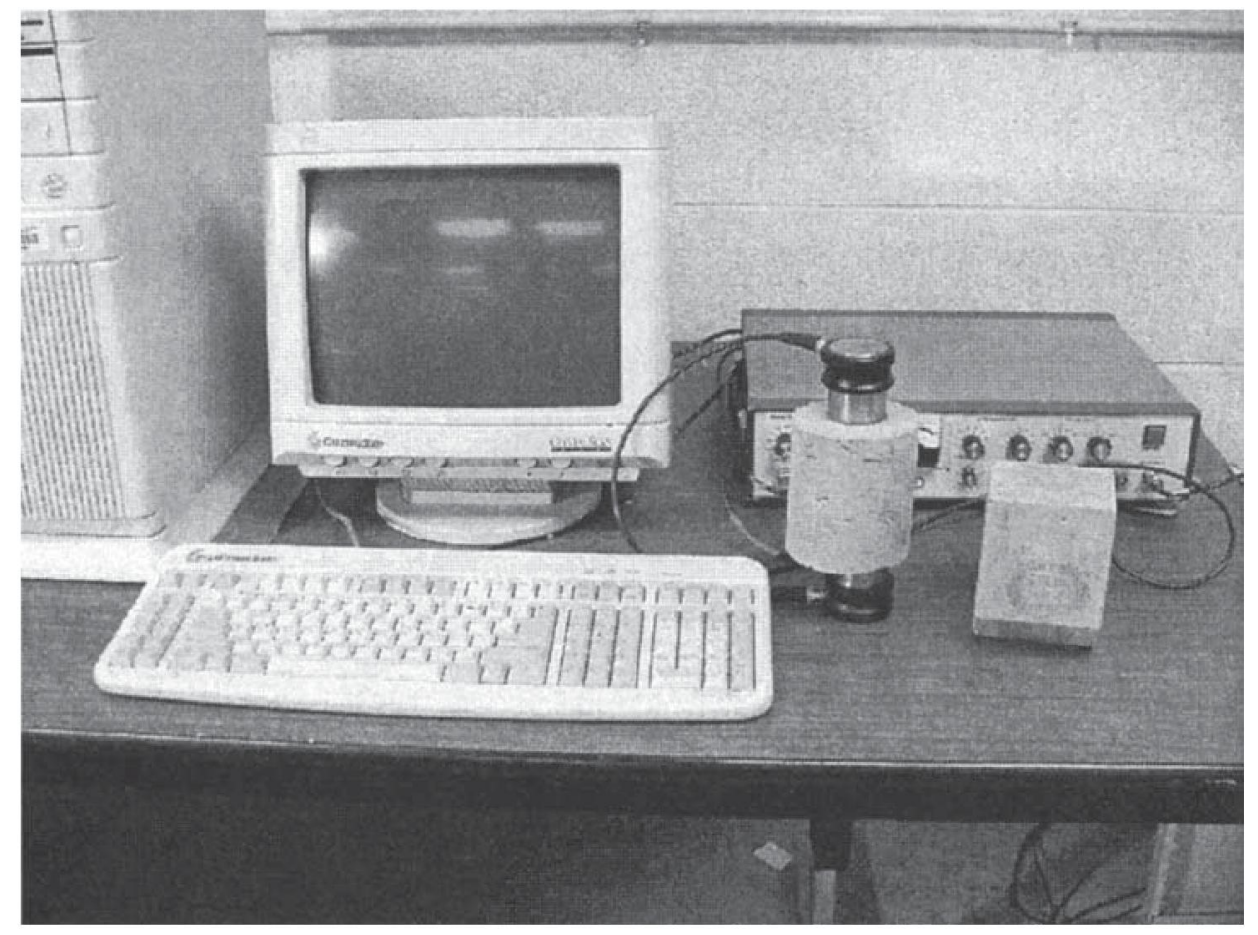

FIG. 1-Test setup. 

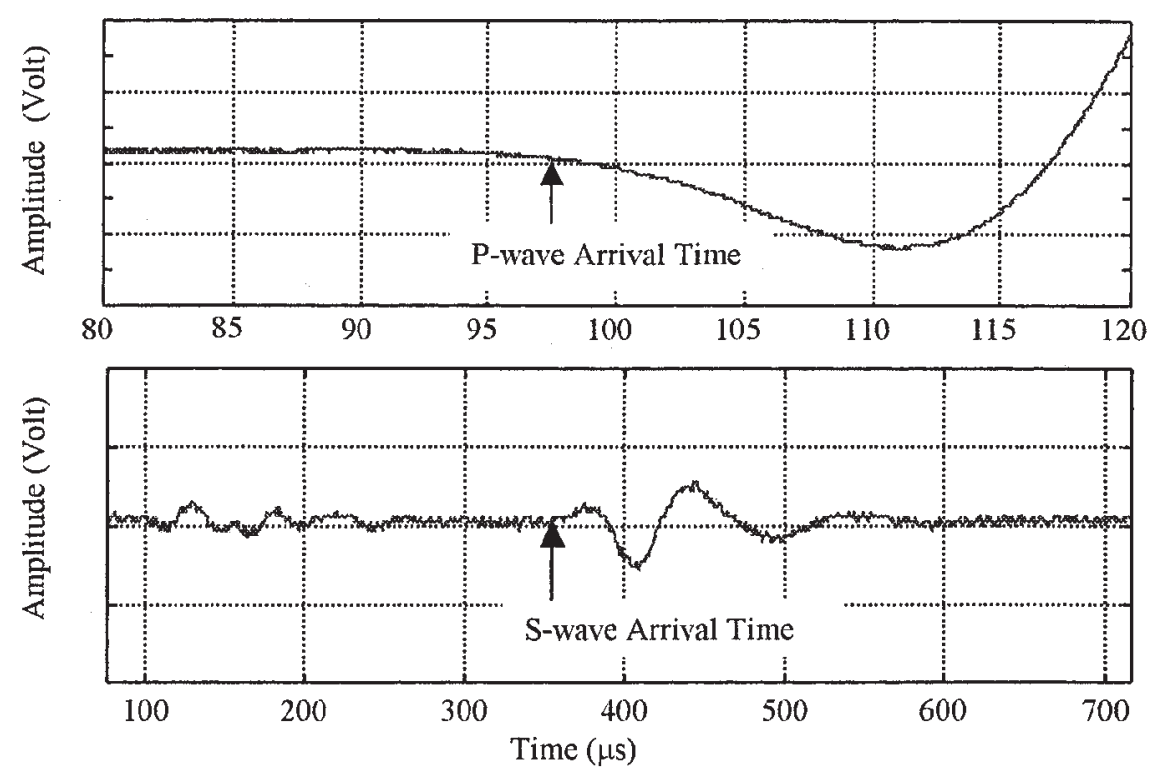

FIG. 2-P-wave and $S$-wave arrival times for a sample.

TABLE 2-Velocity measurements for Ottawa sand.

\begin{tabular}{lcc}
\hline Wave Type & Stress & Velocity, ft/s \\
\hline \multirow{2}{*}{ P-wave } & $0.82^{1}$ & 933 \\
& $1.79^{1}$ & 1036 \\
& $3.72^{1}$ & 1166 \\
S-wave & $6.33^{1}$ & 1333 \\
& $258^{2}$ & 518 \\
& $536^{2}$ & 583 \\
& $912^{2}$ & 639 \\
\hline
\end{tabular}

\footnotetext{
${ }_{2}^{1} \mathrm{psi}$, for comparison to published data.

${ }^{2} \mathrm{psf}$, for comparison to published data.

All measurements are conducted at a void ratio of approximately 0.53 for comparison to published data.
} 

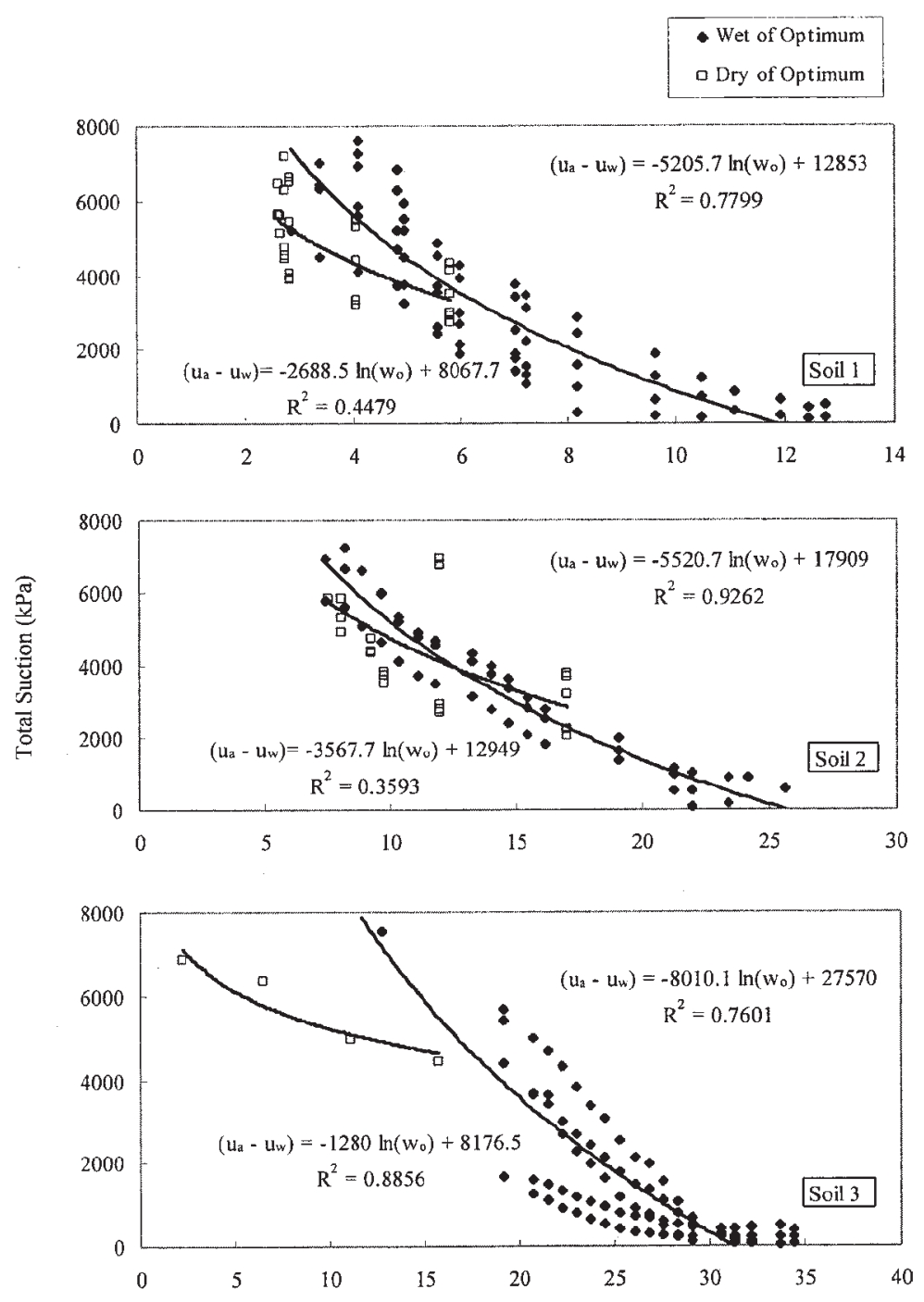

Water Content $(\%)$

FIG. 3-Variation of total suction with water content. 


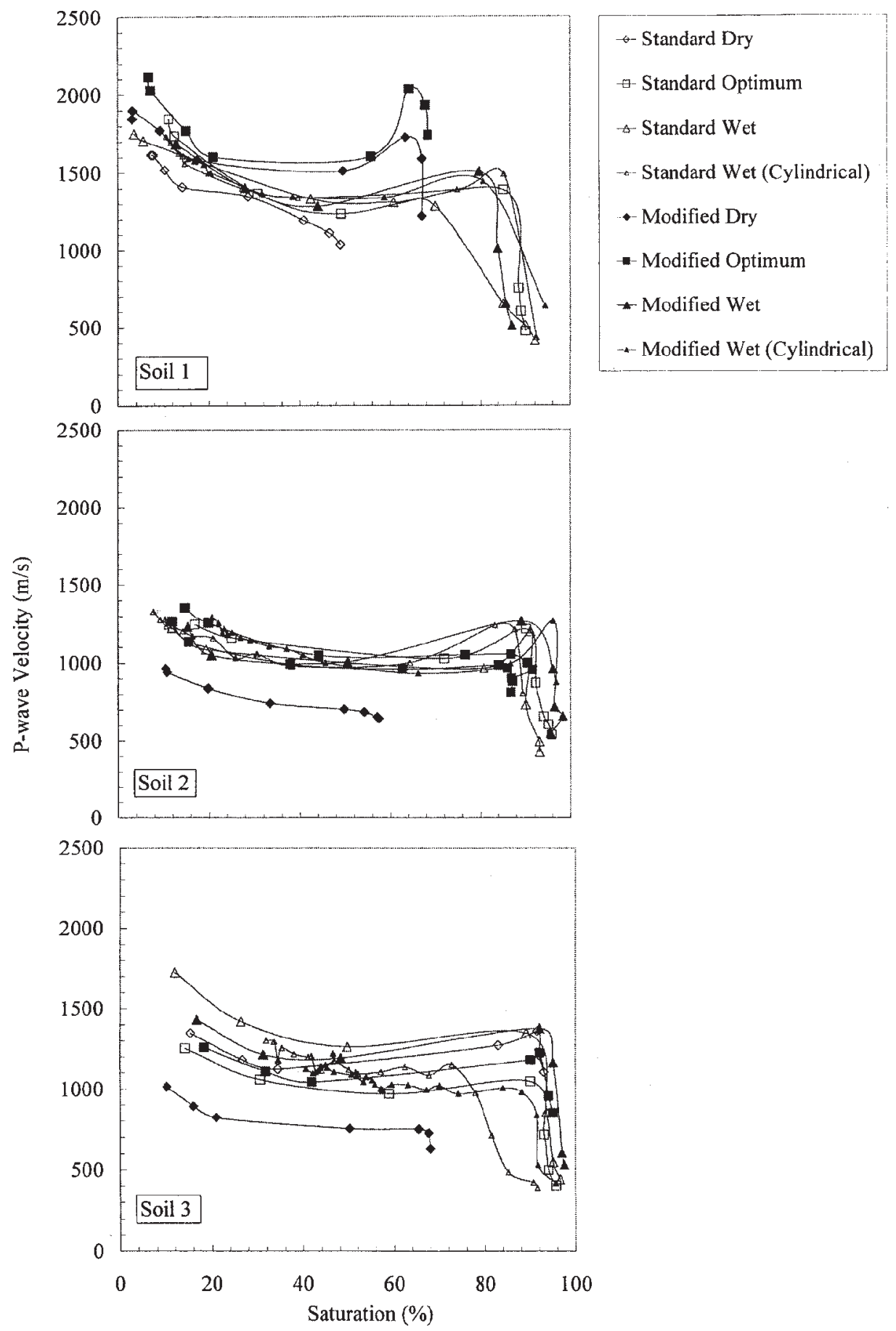

FIG. 4a-Variation of $P$-wave velocity with saturation. 



FIG. $4 b$-Variation of S-wave velocity with saturation. 


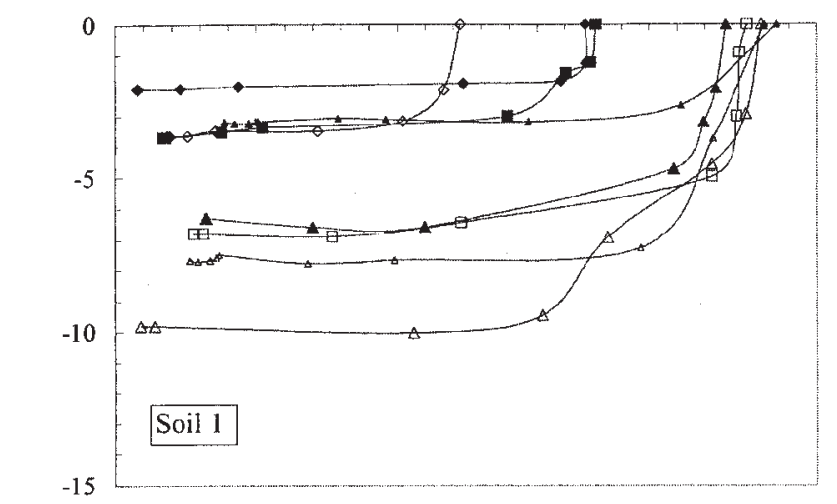

$$
\begin{aligned}
& \text { — Standard Dry } \\
& \text { — Standard Optimum } \\
& \text { «- Standard Wet } \\
& \text { - - Standard Wet (Cylindrical) } \\
& \text { - Modified Dry } \\
& - \text { Modified Optimum } \\
& \text { - Modified Wet } \\
& \text { - Modified Wet (Cylindrical) }
\end{aligned}
$$
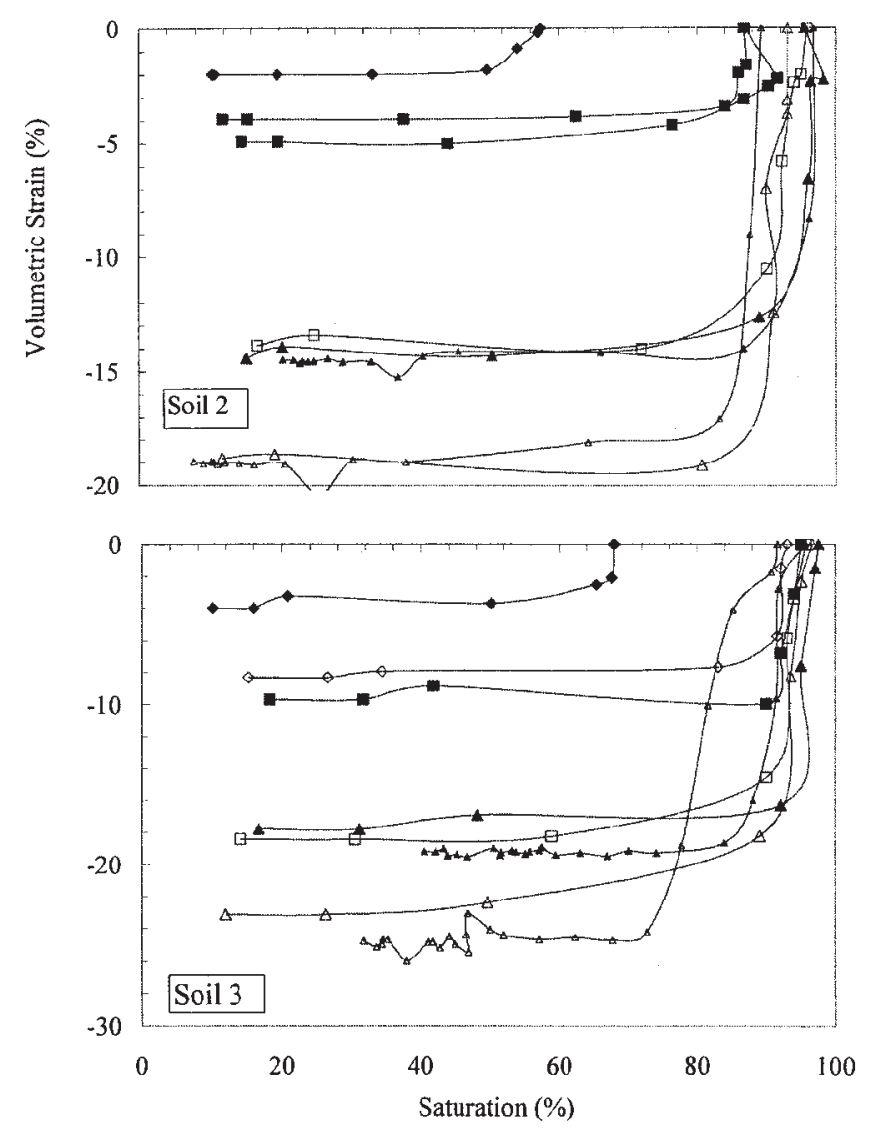

FIG. 5a-Variation of total strain with saturation. 


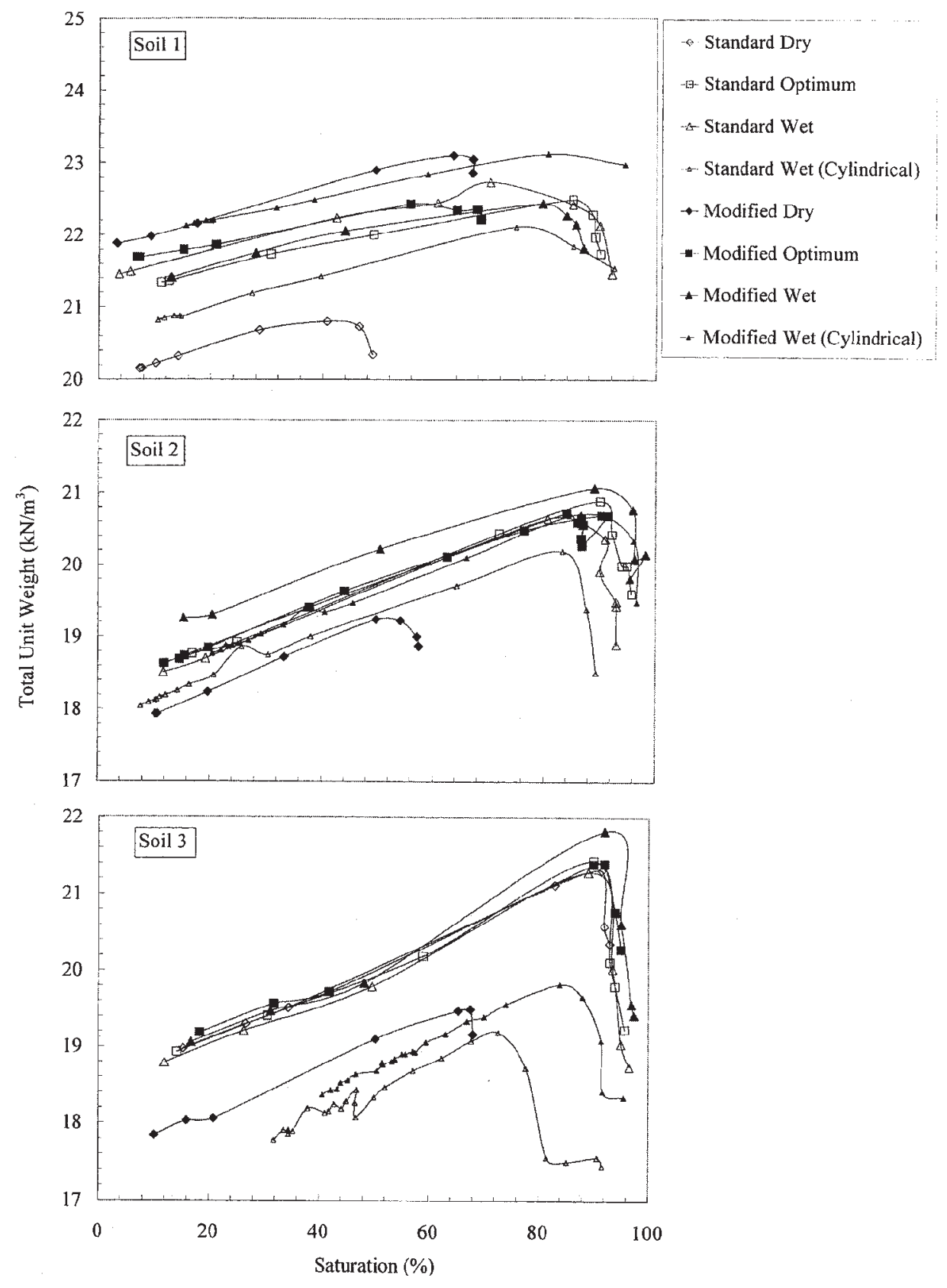

FIG. $5 b$-Variation of total unit weight with saturation. 


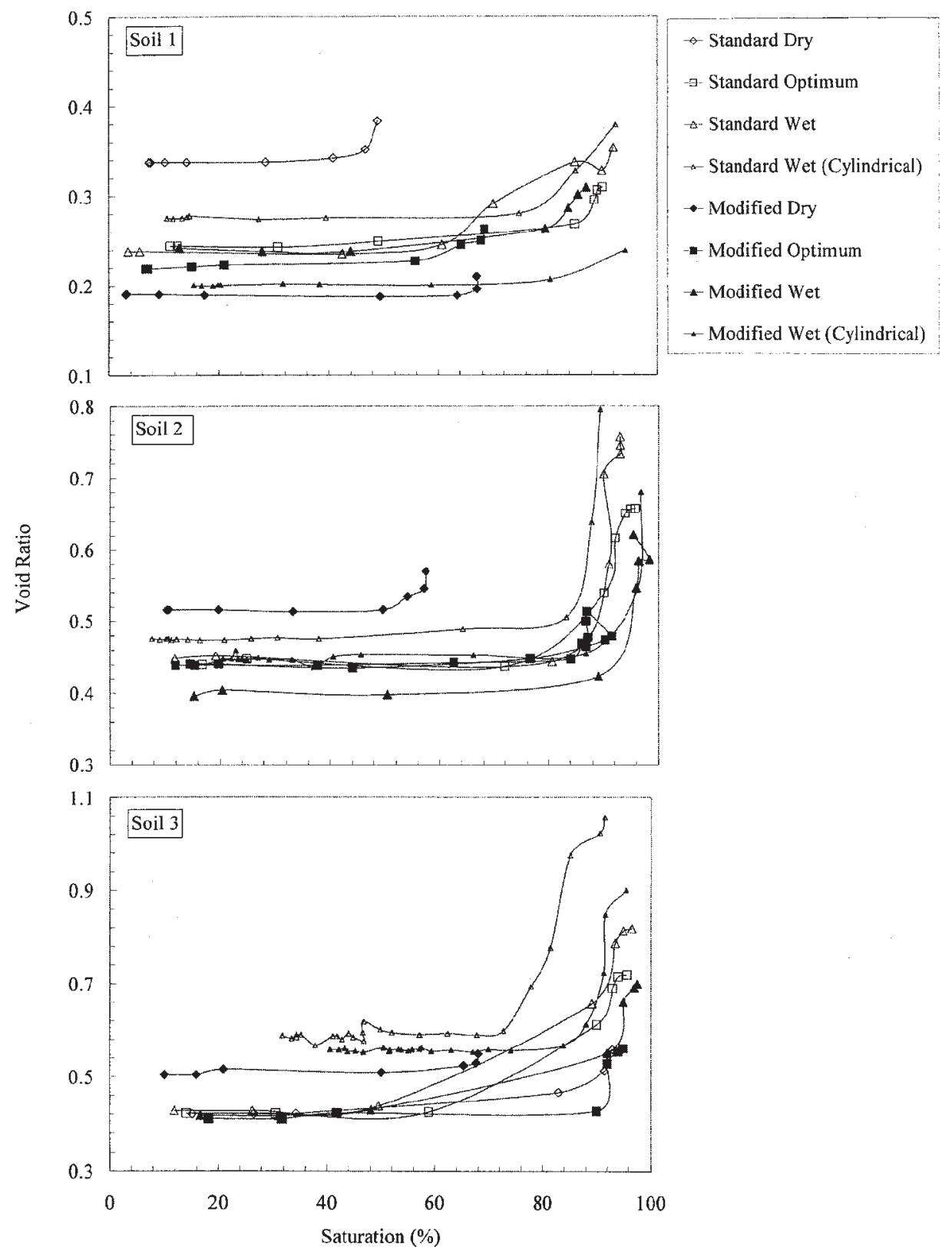

FIG. 5c-Variation of void ratio with saturation. 


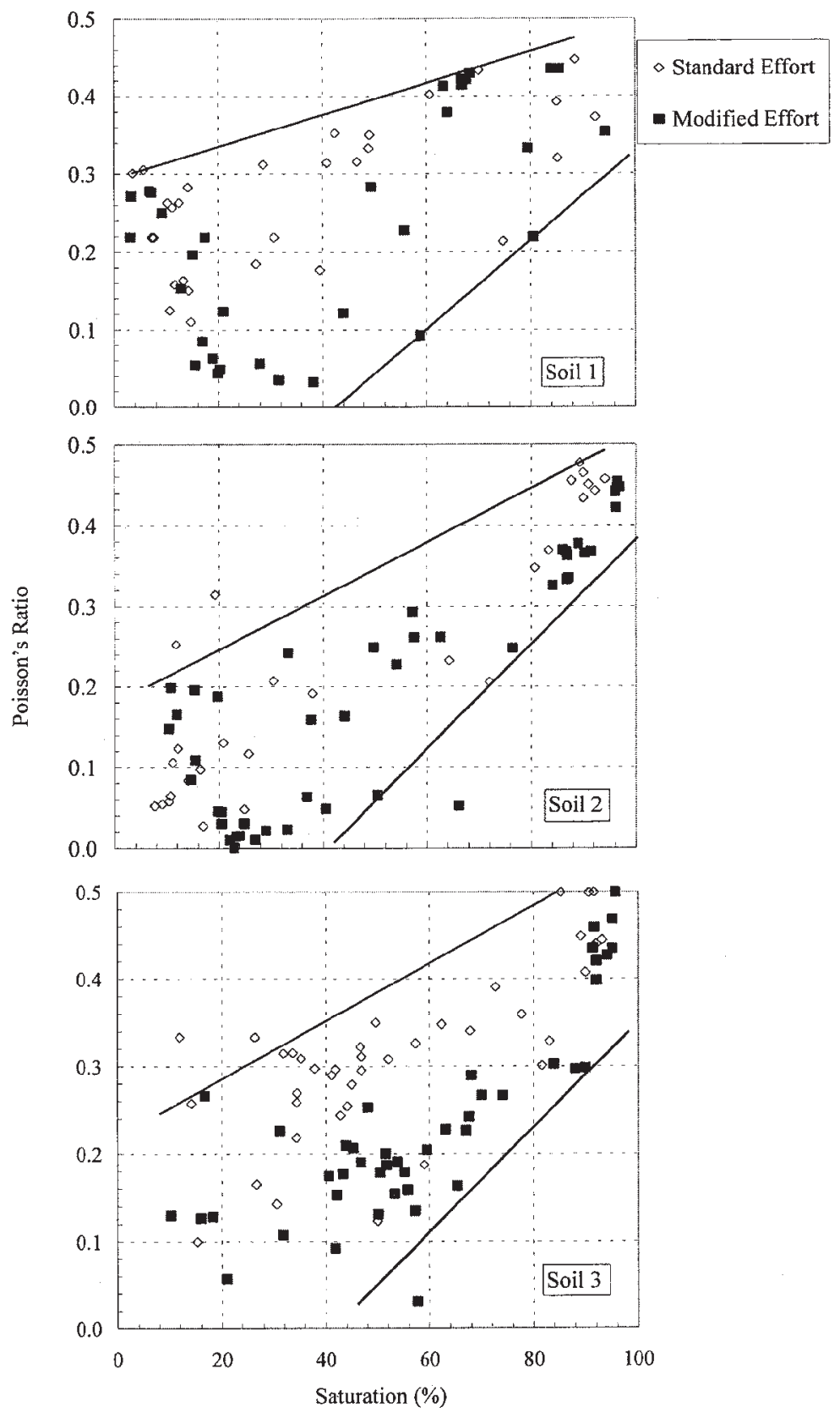

FIG. 6-Isotropic Poisson's ratio. 

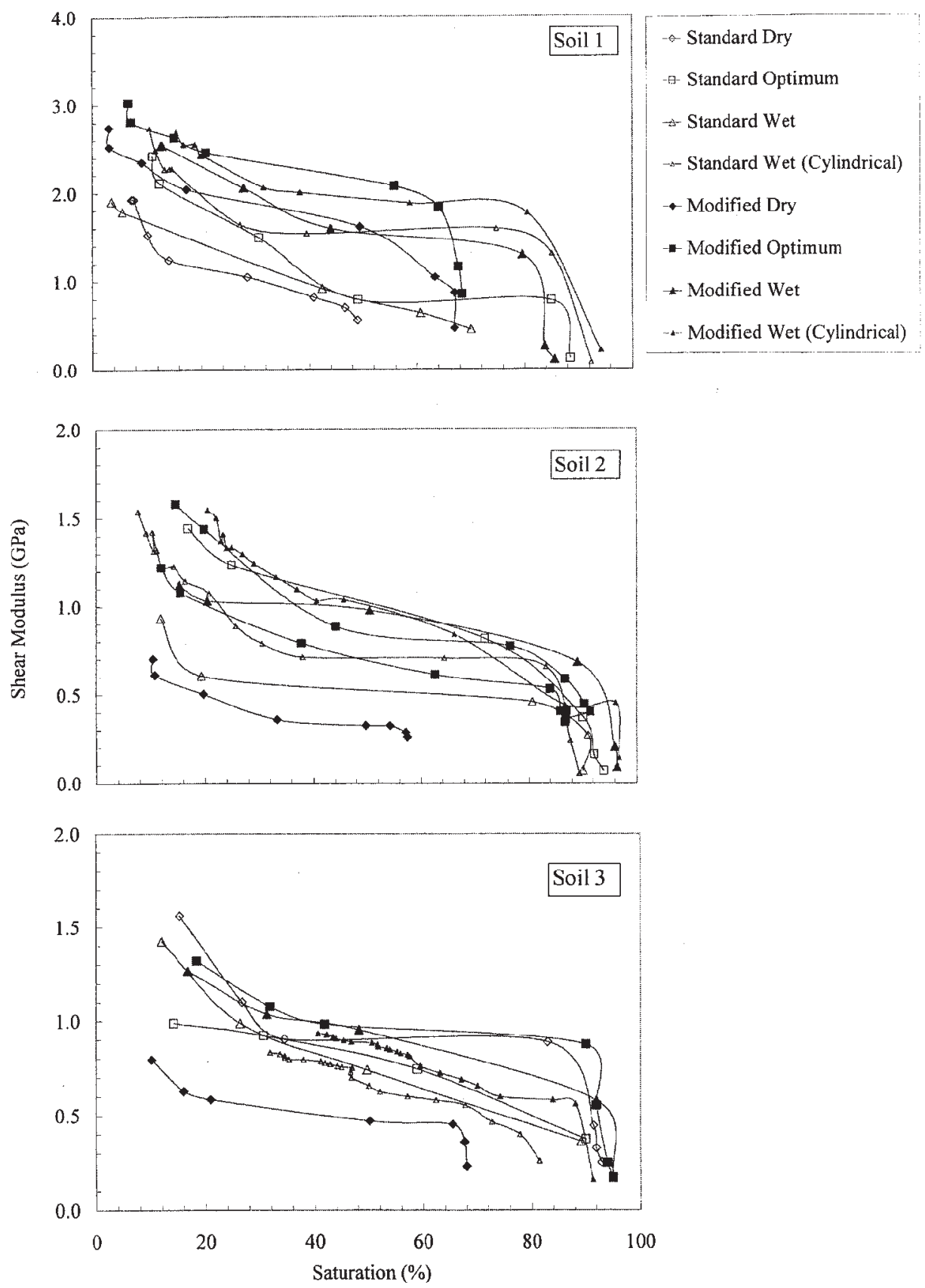

FIG. 7-Variation of measured shear modulus with saturation. 

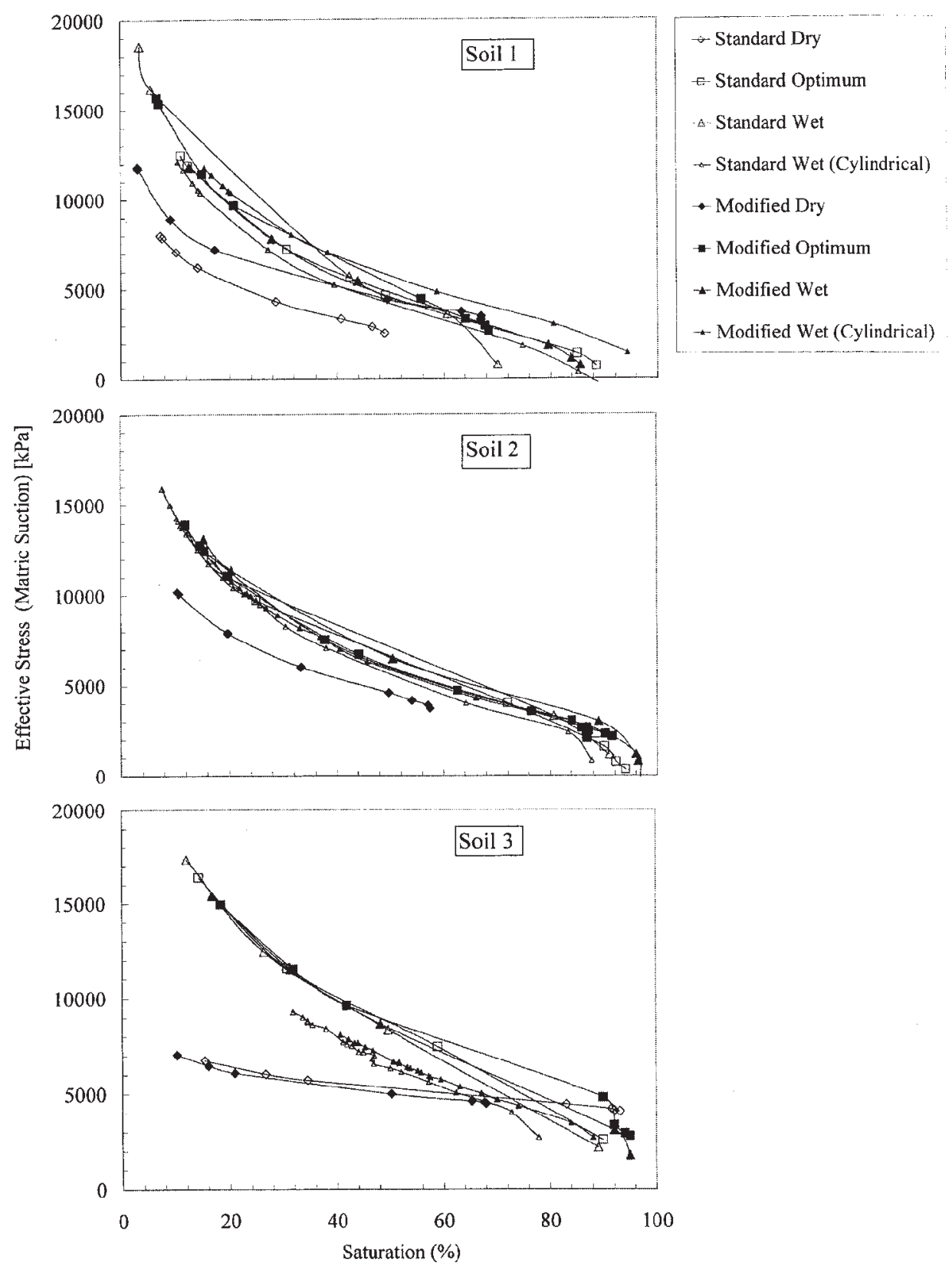

FIG. 8 -Variation of estimated effective stress with saturation. 


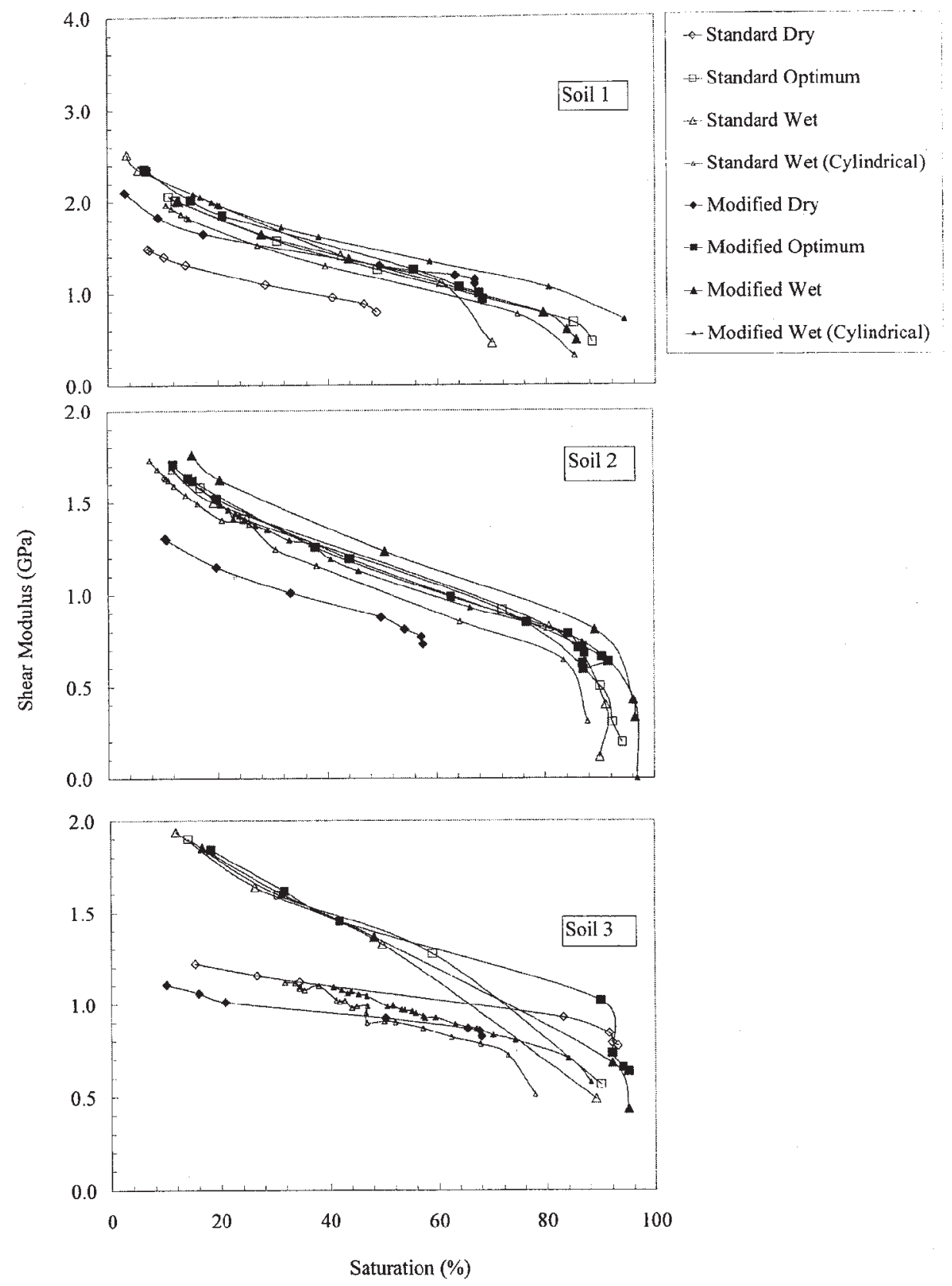

FIG. 9-Variation of predicted shear modulus with saturation. 


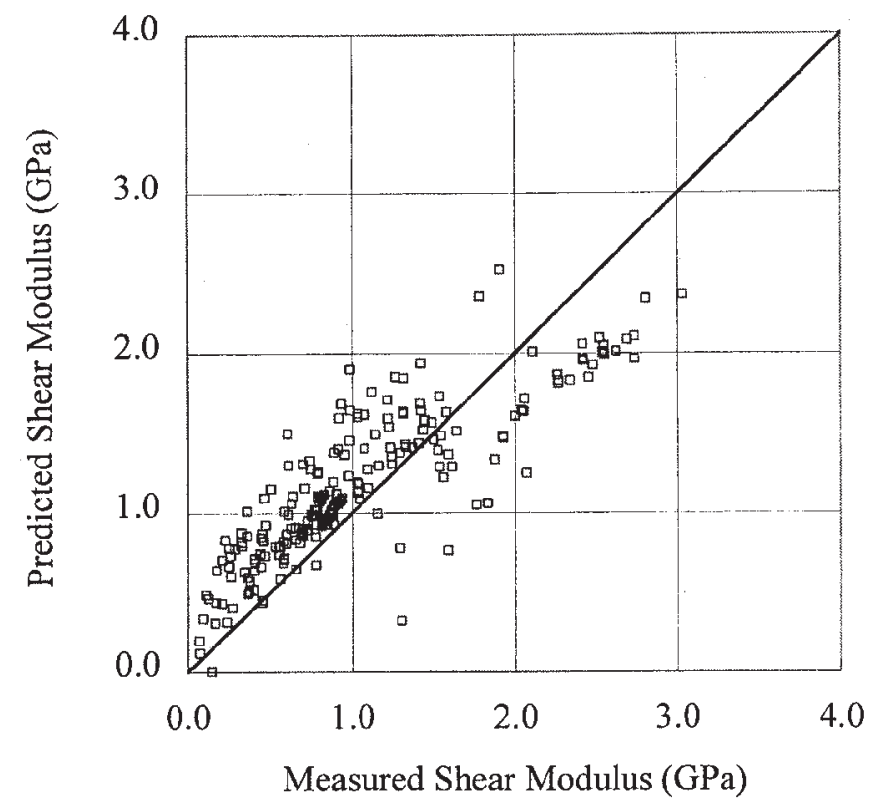

FIG. 10-Measured shear modulus versus predicted shear modulus. 